noted. At T2 IMT-mean remained stable, M-MAX worsened further $(\mathrm{p}<0.05)$. No significant variation in FMD was observed (Table). Noteworthy, from T0 to T2 systolic blood pressure and Body Mass Index remained stable ( $p=n s)$, while diastolic blood pressure decreased $(p=0,001)$. A good response to PsA treatment was confirmed by a significant decrease (T0 vs T1) in Tj, Sj, DAS 28 and CRP $(p<0.01)$; treatment efficacy was preserved from T1 to T2 ( $p=n s)$ (Table).

Conclusions: Our data revealed that in patients with PsA, despite treatment with TNF blockers, there is still a gradual, albeit slight progression of subclinical atherosclerosis assessed by ultrasonography. Other inflammatory mechanisms not related to TNF may be responsible of the progression in atherosclerotic disease.

Disclosure of Interest: None declared

DOI: 10.1136/annrheumdis-2017-eular.5545

\section{AB0746 PRELIMINARY RESULTS OF A TWO-YEAR FOLLOW UP OF SUBCLINICAL ATHEROSCLEROSIS IN PATIENTS WITH PSORIATIC ARTHRITIS}

C. Vergara-Dangond ${ }^{1}$, M. Robustillo-Villarino ${ }^{1}$, V. Núñez-Monje ${ }^{1}$

M. Aguilar-Zamora ${ }^{1}$, L. Montolio-Chiva ${ }^{1}$, E. Valls-Pascual ${ }^{2}$, A. Ybáñez-García ${ }^{1}$, Á. Martínez-Ferrer ${ }^{2}$, J.J. Alegre-Sancho ${ }^{1} .{ }^{1}$ Rheumatology; ${ }^{2}$ Hospital

Universitario Dr. Peset, Valencia, Spain

Background: Psoriatic arthritis (PsA) is a disease associated with an increased cardiovascular (CV) risk, due to early atherosclerosis, which is comparable to a rheumatoid arthritis population. However, there is a lack of studies that evaluate the progression of subclinical atherosclerosis over a year in these patients.

Objectives: To explore the progression of the vascular damage by different techniques in patients with PsA and the factors related with these changes.

Methods: Pre-post study with analytical components. 44 patients with PsA (CASPAR criteria) and peripheral joint involvement of more than one year since diagnosis were consecutively included. We gathered demographic (age, gender, BMI), clinical (traditional CV risk factors, previous CV event), and analytical variables (atherogenic index [Al], GFR [MDRD], fibrinogen, glycated hemoglobin, CRP, ESR, ultrasensitive CRP, apoB/apoA1 ratio) and basal CV risk was estimated with SCORE tool. Other variables were collected retrospectively from patients electronic medical record. The extracranial branches of carotid artery were explored by ultrasonography (US) using an Esaote MyLab70XVG with a 7-12 MHz linear transducer and an automated program measuring intimamedia thickness (IMT) through radiofrequency ( ${ }^{\mathrm{RF}} \mathrm{QIMT}$ ), and the presence of atheroma plaques, as per the Mannheim consensus, was registered. Pulse wave velocity (PWV) was determined, as an arterial stiffness marker, by a validated MobilOGraph ${ }^{\circledR}$ device. Patients were followed during a 2-year period between may 2014 until december 2016. All of the tests were repeated after 2 years. Statistical analysis was performed using SPSS 17.0 software.

Results: We analyzed 38 patients, excluding those with high $\mathrm{CV}$ risk (previous $\mathrm{CV}$ event, GFR $<60 \mathrm{mg} / \mathrm{dl}$, and/or type II or type I diabetes with organ affection) and followed during 2 years. At baseline, the mean and median of age was 59,2 and 60,5 years (39-88), respectively, mostly women $(65,8 \%)$. The median BMI was $28(17-35) .28,9 \%$ were smokers and $36,8 \%$ had hypertension. $26,3 \%$ received glucocorticoids, $57,9 \%$ NSAIDs, $84,2 \%$ DMARDs and $31,6 \%$ biologic therapies. The median CRP, ESR and DAS 28 were $5 \mathrm{mg} / \mathrm{L}(1-19,1), 7 \mathrm{~mm} / \mathrm{h}(2-28)$ and $2,17(1,24-3,7)$, respectively. The median SCORE was $1(0-7)$, the PWV was 8 $\mathrm{m} / \mathrm{s}(5,6-13,5)$ and basal IMT was $728 \mu(462-1087)$; the presence of atheroma plaques was detected in $35,1 \%$ of the patients.

After 2 years, plaque appearance was seen in $15 \%$ more of patients, as well as worsening of PWV and IMT in 56,8\% and $38,9 \%$ of patients, respectively. These changes were not significant. No patient developed a CV event.

In the bivariate analysis, PWV progression at 2 years related with advanced age $(p<0,002)$, and with elevated SCORE $(p<0,044)$, and showed a tendency with higher arterial systolic pressure (ASP). We also observed a tendency to an association between plaque appearance, age and ASP; as well as lower apolipoprotein A1 levels with IMT.

Conclusions: The progression over time of the vascular damage in patients with PsA relates with traditional CV risk factors. These preliminary results must be confirmed in a posterior analysis with a greater number of patients.

Disclosure of Interest: None declared

DOI: 10.1136/annrheumdis-2017-eular.3002

\section{AB0747 THE EFFECT OF CERTOLIZUMAB PEGOL ON RADIOGRAPHIC PROGRESSION OVER 4 YEARS OF TREATMENT IN PATIENTS WITH PSORIATIC ARTHRITIS}

D. van der Heijde ${ }^{1}$, R. Fleischmann ${ }^{2}$, J. Wollenhaupt ${ }^{3}$, A. Deodhar ${ }^{4}$, L. Bauer ${ }^{5}$, B. Hoepken ${ }^{5}$, L. Peterson 6 , P.J. Mease ${ }^{7} .{ }^{1}$ Leiden University Medical Center, Leiden, Netherlands; ${ }^{2}$ UT Southwestern Medical Center and Dallas Metroplex Clinical Research Center, Dallas, United States; ${ }^{3}$ Schön Klinik, Hamburg, Germany; ${ }^{4}$ Oregon Health and Science University, Portland, United States; ${ }^{5}$ UCB Pharma, Monheim, Germany; ${ }^{6}$ UCB Pharma, Raleigh; ${ }^{7}$ Swedish Medical Center and University of Washington, Seattle, United States

Background: The RAPID-PsA trial (NCT01087788) investigated the efficacy and safety of certolizumab pegol (CZP) in patients (pts) with psoriatic arthritis (PsA).
It demonstrated that CZP treatment inhibits radiographic progression over 96 weeks (wks).

Objectives: We report the long-term effect of CZP treatment on radiographic progression in pts with PsA over 4 years.

Methods: The RAPID-PsA phase 3 trial was double-blind and placebo-controlled to Wk24, dose-blind to Wk48, and open-label (OL) to Wk216. Pts had active PsA and had failed $\geq 1$ DMARD. Pts randomized to CZP (200mg Q2W or 400mg Q4W, following $400 \mathrm{mg}$ loading dose at Wks0, 2, 4) continued their assigned dose in the OL period. Radiographs taken at baseline (BL), and at Wks96, 168, 216, were read in a single reading campaign using the modified Total Sharp Score (mTSS) for PsA by 2 readers, blinded to patient information and time point sequence. The mean of the scores of the 2 readers was used. Outcomes reported are the least squares (LS) mean mTSS score, change from BL (CFB) in mTSS score, and the percentage of pts assessed for radiographic damage who achieved mTSS non-progression (defined either as CFB in mTSS score $\leq 0.5$ or $\leq 0$ ), for all Wk0 CZP-treated pts, irrespective of dose regimen. mTSS score and CFB were estimated using Mixed Model Repeated Measures (MMRM) estimates; proportions of pts with radiographic non-progression are presented as observed case.

Results: 409 PsA pts were randomized, of whom 273 received CZP from Wk0. The LS mean BL mTSS score was 16.0 and there was little increase from BL in mTSS score to Wk216 (Table). Amongst those who completed the study to Wk216, the majority of CZP-treated pts achieved radiographic non-progression to Wk216, both with non-progression defined as CFB in mTSS score $\leq 0.5$ or $\leq 0$ (Table). The change in LS mean mTSS score over time for WkO CZP-treated pts was consistently low throughout the trial: $0.14(95 \% \mathrm{Cl}$ : $0.02-0.26)$ per 48 wks from BL to Wk96, and 0.18 (95\% Cl: 0.08-0.28) per 48 wks from Wk96 to Wk216.

Table: $\mathrm{mTSS}$ score and radiographic non-progression to Week 216 for patients treated with CZP from Week 0

\begin{tabular}{|c|c|c|c|c|}
\hline & \multicolumn{4}{|c|}{ Week O CZP dose combined ( $N=273$ ) } \\
\hline & Week 0 & Week 96 & Week 168 & Week 216 \\
\hline $\begin{array}{l}\text { mTSS score, } \\
\text { LS mean (SE) } \\
{[95 \% \text { Cl] [a] }}\end{array}$ & $\begin{array}{c}16.0(2.2) \\
{[11.6-20.4]}\end{array}$ & $\begin{array}{c}16.2(2.2) \\
{[11.8-20.6]}\end{array}$ & $\begin{array}{c}16.6(2.3) \\
{[12.1-21.0]}\end{array}$ & $\begin{array}{c}16.7(2.3) \\
{[12.2-21.1]}\end{array}$ \\
\hline $\begin{array}{l}\text { CFB in mTSS score, } \\
\text { LS mean (SE) } \\
{[95 \% \mathrm{Cl}[\mathrm{a}]}\end{array}$ & - & $\begin{array}{l}0.3(0.1) \\
{[0.0-0.5]}\end{array}$ & $\begin{array}{l}0.6(0.2) \\
{[0.3-1.0]}\end{array}$ & $\begin{array}{c}0.7(0.2) \\
{[0.3-1.1]}\end{array}$ \\
\hline
\end{tabular}

Non-progression rate, $n(\%)[b]$ $\mathrm{mTSS} \leq 0.5, \mathrm{n} / \mathrm{N}(\%)$

Patiento with CFB in $\mathrm{mTSS} \leq 0, \mathrm{n} / \mathrm{N}(\%)$

$-$
$180 / 214(84.1)$ $158 / 196(80.6)$ $145 / 186(78.0)$ [a] Mixed Model Repeated Measures (MMRM) estimates; [b] Observed case; percentage of patients with non-progression, as a proportion of the number assessed for progression. CFB: change from baseline; LS: least squares; SE: standard error.

Conclusions: There was little radiographic progression in CZP-treated PsA pts, as measured by mTSS, throughout the 4-year RAPID-PsA trial. References:

[1] Mease P. RMD Open 2015;1:e000119;doi:10.1136/rmdopen-2015-000119. Acknowledgements: This study was funded by UCB Pharma. We thank the patients and their caregivers in addition to the investigators and their teams who contributed to this study. Editorial services were provided by Costello Medical Consulting.

Disclosure of Interest: D. van der Heijde Consultant for: AbbVie, Amgen, Astellas, AstraZeneca, BMS, Boehringer Ingelheim, Celgene, Daiichi, Eli Lilly, Galapagos, Gilead, Janssen, Merck, Novartis, Pfizer, Regeneron, Roche, Sanofi, UCB Pharma, Employee of: Director of Imaging Rheumatology B.V., R. Fleischmann Grant/research support from: Genentech Inc, Roche, Abbott, Amgen, UCB Pharma, Pfizer, Bristol-Myers Squibb, Eli Lilly, Sanofi-Aventis, MSD Pharmaceuticals, Novartis, AstraZeneca, Janssen, Consultant for: Roche, Abbott, Amgen, UCB Pharma, Pfizer, Bristol-Myers Squibb, Eli Lilly, Sanofi-Aventis, Novartis, AstraZeneca, Janssen, J. Wollenhaupt Grant/research support from: UCB Pharma, Consultant for: UCB Pharma, A. Deodhar Grant/research support from: AbbVie, Amgen, Eli Lilly, GlaxoSmithKline, Janssen, Novartis, Pfizer, UCB Pharma, Consultant for: Eli Lilly, Janssen, Novartis, Pfizer, UCB Pharma, L. Bauer Employee of: UCB Pharma, B. Hoepken Employee of: UCB Pharma, L. Peterson Employee of: UCB Pharma, P. Mease Grant/research support from: (Abbott) AbbVie, Amgen, Bristol-Myers Squibb, Celgene, Janssen, Eli Lilly, Novartis, Pfizer, Sun, UCB Pharma, Consultant for: (Abbott) AbbVie, Amgen, Bristol-Myers Squibb, Celgene, Crescendo, Corrona, Dermira, Janssen, Eli Lilly, Merck, Novartis, Pfizer, Sun, UCB Pharma, Zynerba, Speakers bureau: (Abbott) AbbVie, Amgen, Bristol-Myers Squibb, Celgene, Crescendo, Genentech Inc, Janssen, Novartis, Pfizer, UCB Pharma

DOI: 10.1136/annrheumdis-2017-eular.1961 